
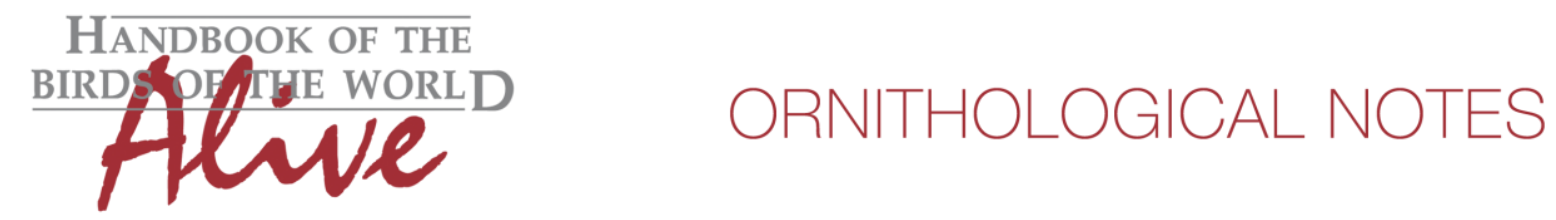

\title{
Notes on the vocalizations of Common Blackbird (Turdus merula)
}

Peter Boesman

In the following we briefly analyze and compare voice of the different races of Common Blackbird (Turdus merula). We also try to quantify the extent of any vocal differences using the criteria proposed by Tobias et al. (2010), as a support for taxonomic review. We have made use of sound recordings available on-line from Xeno Canto (XC).

We are particularly interested to compare voice of races mandarinus, sowerby and intermedius with other races, as these have been suggested to merit full species rank (HBW Alive, Collar 2016).

An overview illustrated with sonograms:

mandarinus/sowerbyi

All song strophes contain several repeated notes, and lack a high-pitched ending:

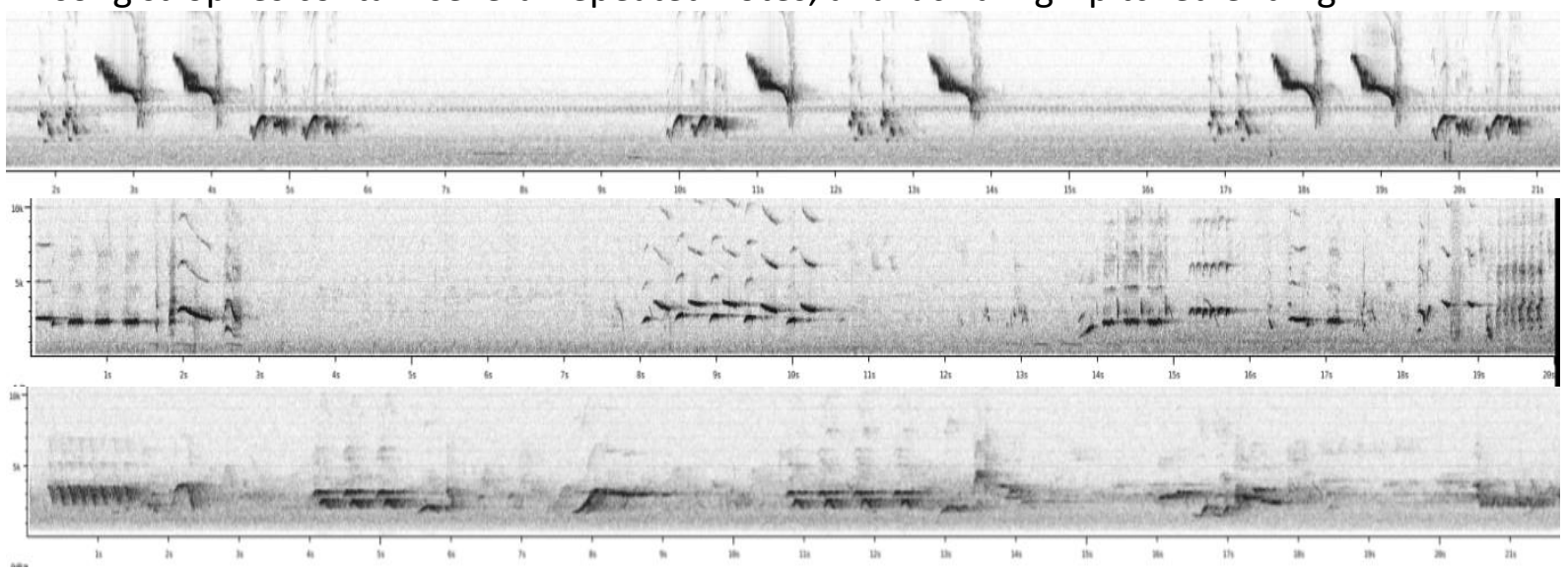

\section{intermedius}

Song sounds like a 'typical' Common Blackbird with different low-pitched whistles gradually building up towards a higher-pitched ending, in every strophe:

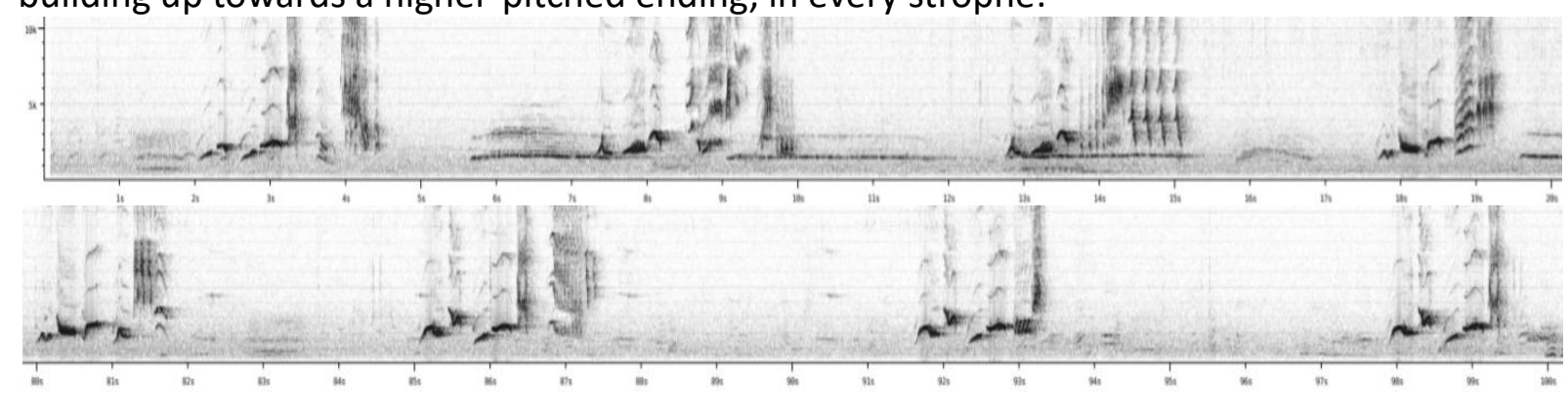

Other races for comparison: 


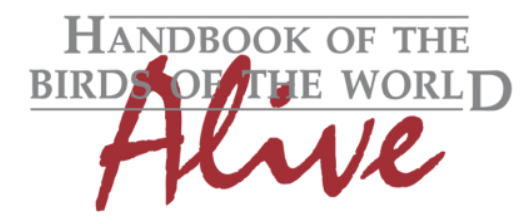

\section{ORNITHOLOGICAL NOTES}

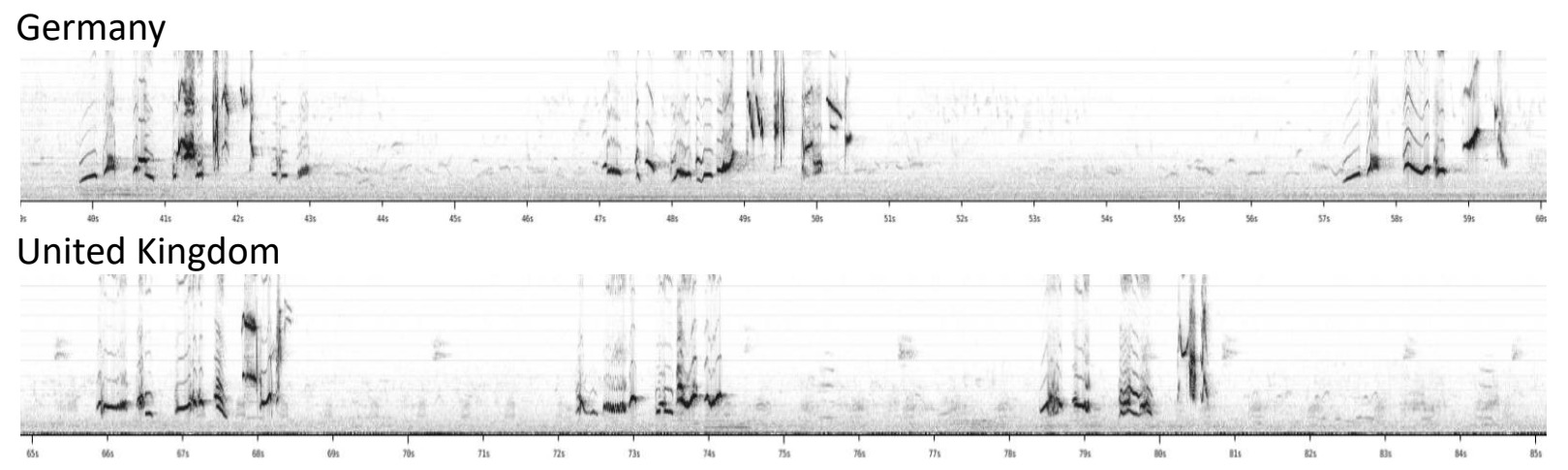

Azores

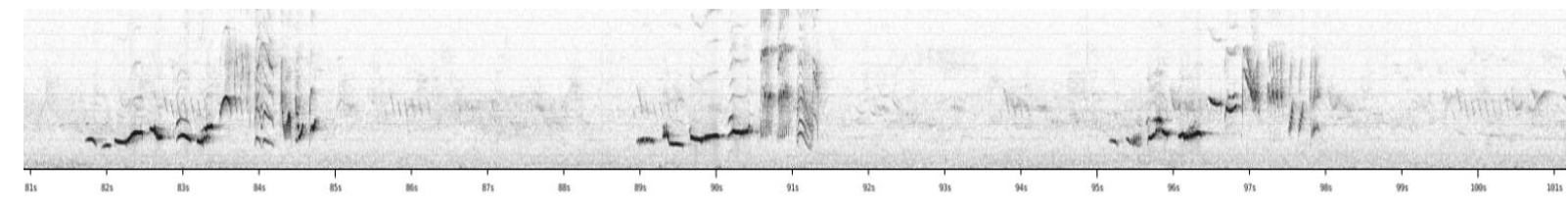

Morocco

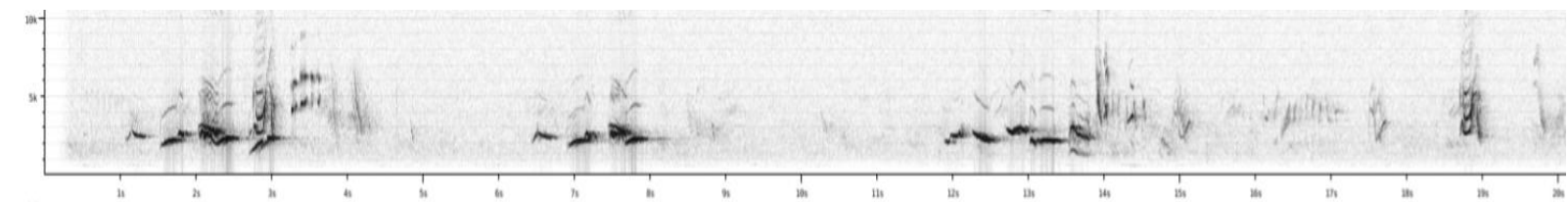

The vocal difference of races mandarinus/sowerbyi is striking in comparison with all other races (it is actually closer to Indian Blackbird Turdus simillimus vocally).

intermedius on the other hand is vocally similar to other races.

Based on the much larger \# of repeated notes per phrase (score 2-3) and the lack of a highpitched ending to the song strophe (measured by average end. freq. or difference in frequence first part vs. last part of song strophe, score 2-3), mandarinus/sowerbyi could be given a total vocal score of about 5 .

This note was finalized on 19th April 2016, using sound recordings available on-line at that moment. We would like to thank in particular the many sound recordists who placed their recordings for this species on $\mathrm{XC}$.

\section{References}

Collar, N. (2016). Common Blackbird (Turdus merula). In: del Hoyo, J., Elliott, A., Sargatal, J., Christie, D.A. \& de Juana, E. (eds.). Handbook of the Birds of the World Alive. Lynx Edicions, Barcelona. (retrieved from http://www.hbw.com/node/58261 on 19 April 2016).

Tobias, J.A., Seddon, N., Spottiswoode, C.N., Pilgrim, J.D., Fishpool, L.D.C. \& Collar, N.J. (2010). Quantitative criteria for species delimitation. Ibis 152(4): 724-746. 


\section{Recommended citation}

Boesman, P. (2016). Notes on the vocalizations of Common Blackbird (Turdus merula). HBW Alive Ornithological Note 304. In: Handbook of the Birds of the World Alive. Lynx Edicions, Barcelona. (retrieved from http://www.hbw.com/node/1251760 on 14 October 2016). 